\title{
Body Fat was Related with Sedentary Time, but not with Moderate-Vigorous Physical activity time in type 2 diabetes
}

K. W. Min1, T.S. Shon2, I.B. Park3, E.S. Kim4, H.J. Kim5, K.A. Han6, S.A. Chang7, K.H. An8, J.M. Yu9, H.R. Kwon10, J.Y. Jung10.

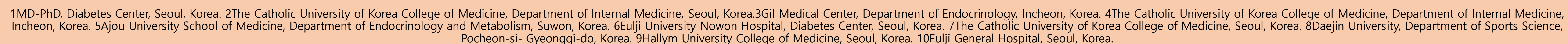

\section{Background}

- Persons with type 2 diabetes were encouraged to undertake at least $150 \mathrm{~min} /$ week of moderate to vigorous aerobic exercise spread out during at least 3 days during the week, with no more than 2 consecutive days between bouts of aerobic activity.

- Sedentary behavior has emerged as a new risk factor for cardiovascular accident.

- The ADA (American diabetes association) recently announced updated, comprehensive guidelines for regular, structured physical exercise for everyone with diabetes and recommended less overall sedentary time every day. This is a shift from the Association's previous recommendation of physical movement every 90 minutes of sedentary time.

- Sedentary behavior has emerged as a new risk factor for cardiovascular accident. Body fat is related with all-cause mortality.

\section{Aim}

The aim of this study was whether moderate to vigorous physical activity (MVPA) time or Sedentary time(ST) was related with percent body fat in type 2 diabetes

\section{Method}

- We randomly recruited seventy smart phone user with Type 2 diabetes and investigated sedentary(SPAt), light(LPAt), moderate(MPAt), vigorous physical activity time(VPAt) with wireless activity tracker (fitbit $H R \circledast: F B$ ) for 7 days in free-living conditions.

- We also measured total muscle mass in kilograms $(\mathrm{kg})$, total body fat $(\mathrm{kg})$, and total body fat percentage(\%)

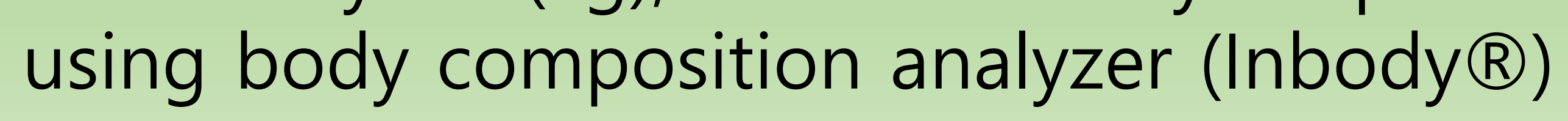

\section{Results}

\section{General Characteristics}

\begin{tabular}{ll}
\hline Male: Female & $64.7 \%$ \\
\hline Age & $60.4 \pm 7.9$ years \\
\hline Body mass index, & $25.6 \pm 3.6 \mathrm{~kg} \cdot \mathrm{m}^{2}$ \\
\hline Duration of diabetes; & $12.5 \pm 7.7$ years \\
\hline A1c & $7.8 \pm 1.3 \%$ \\
\hline Muscle & $42.2 \pm 7.6 \mathrm{~kg}$ \\
\hline Body fat & $20.3 \pm 7.1 \mathrm{~kg}$ \\
\hline Percent fat & $30.9 \pm 7.4 \%$ \\
\hline Recommended fat control & $8.9 \pm 5.9 \mathrm{~kg}$
\end{tabular}

Monitoring 24 hour activity in Elderly type 2 Diabetes Mellitus

- SPAt was $933.9 \pm 219.7$ minutes/day $(73.4 \pm 9.9 \%)$, LPAt was $266.3 \pm 97.5$ minutes/day $(21.8 \pm 9.2 \%)$, MPAt was $25.9 \pm 25.9$ minutes/day $(2.1 \pm 2.1 \%)$, VPAt was $34.2 \pm 34.2$ minutes/day $(2.7 \pm 2.5 \%)$.

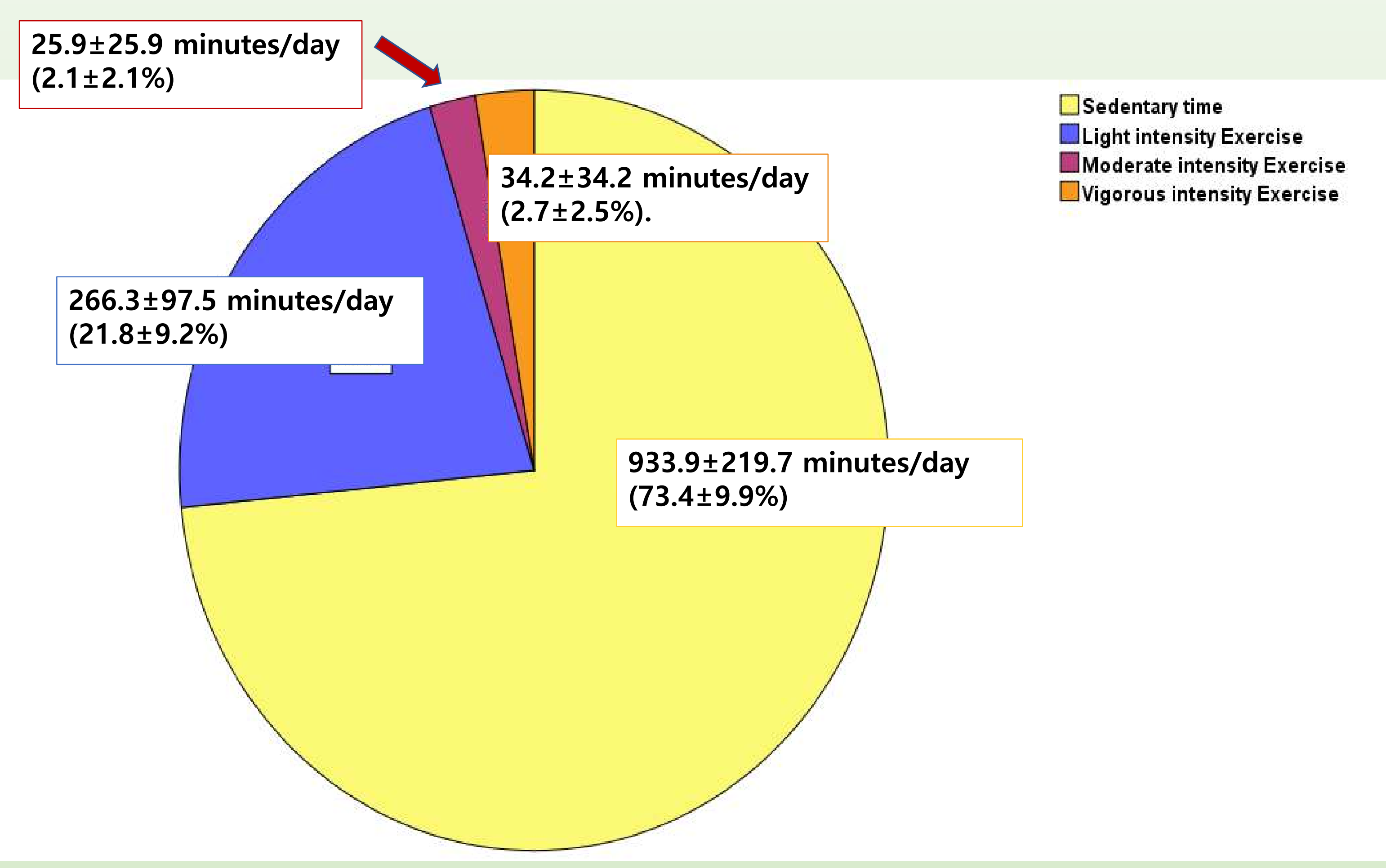

Relations between activity time and percent body fat after adjusted for age, gender, and glycosylated hemoglobin level.

\begin{tabular}{|l|r|c|}
\hline Sedentary (Min/day) & $r$ & $p$ \\
\hline Light Exercise (Min/day) & 0.415 & 0.001 \\
\hline Moderate Exercise (Min/day) & -0.526 & 0.000 \\
\hline Vigorous Exercise (Min/day) & -0.112 & 0.380 \\
\hline Moderate and vigorous Exercise (Min/day) & 0.131 & 0.302 \\
\hline Similar results were found in 48 persons who had \\
\hline
\end{tabular}

Relations between HOMA-IR and activity time

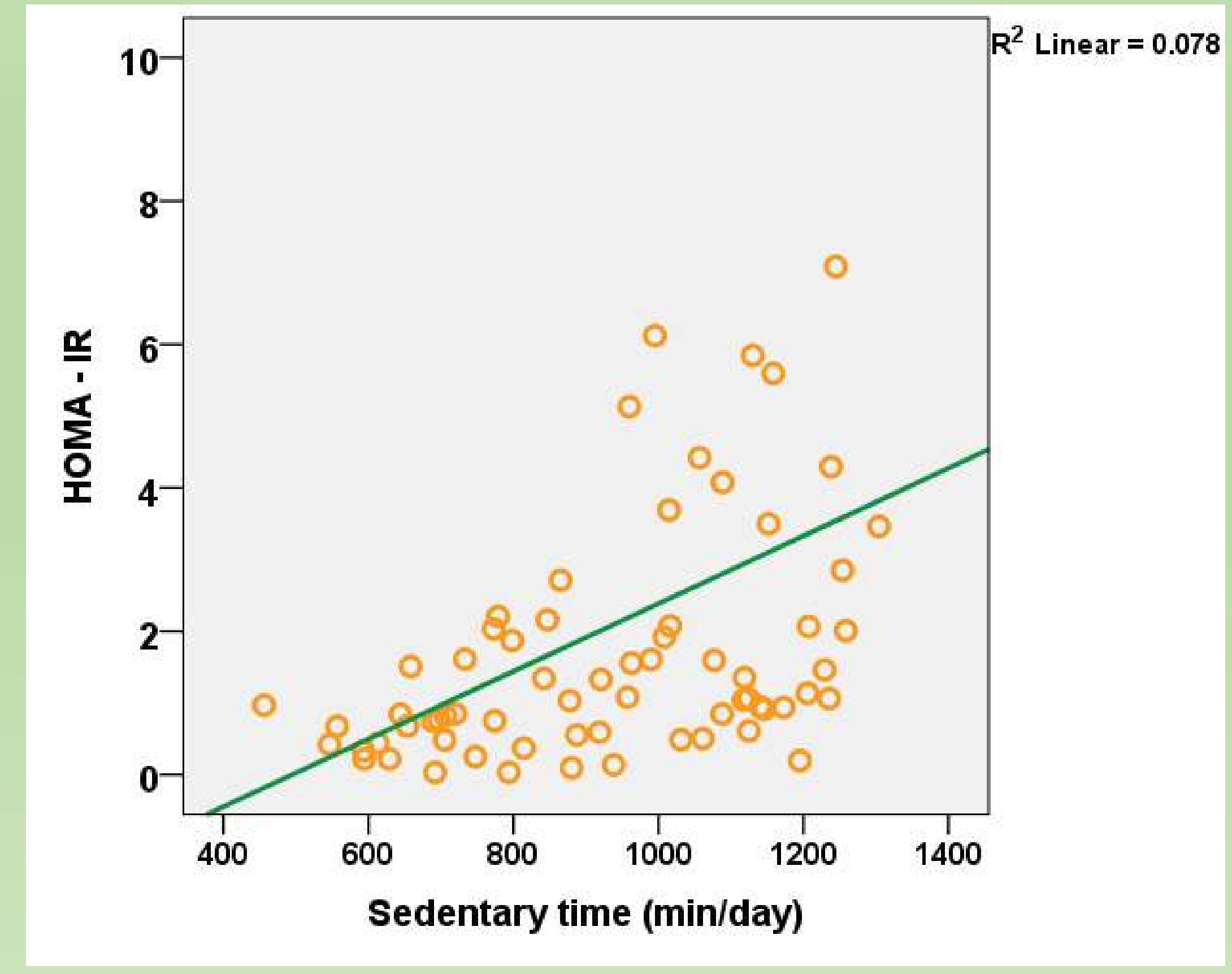

HOMA IR was correlated with sedentary time $(r=0.280$, $P=0.021$ )

\section{Conclusion,}

- Longer sedentary time was related with higher body fat in type 2 diabetes.

- These results supported the validity of the new recommendations about less sedentary time in type 2 diabetes mellitus from the American Diabetes 